\title{
Influence of Plant Spacing on Seed and Ware Tuber Production of Potato (Solanum tuberosum L.) Cultivars Grown in Eastern Ethiopia
}

\author{
Tesfa Binalfew $^{1^{*}}$, Nigussie Dechassa ${ }^{2}$ and Tamado Tana ${ }^{2}$ \\ ${ }^{1}$ Melkassa Agricultural Research Centre, P.O. Box: 436, Adama, Ethiopia \\ ${ }^{2}$ Department of Plant Science, Haramaya University, P.O. Box: 38, Dire Dewa, Ethiopia
}

\begin{abstract}
Plant spacing is an important agronomic consideration in the production of potato (Solanum tuberosum L.). However, the spacing of $30 \mathrm{~cm}$ between seed tubers and $75 \mathrm{~cm}$ between rows has been invariably used across all parts of Ethiopia. The practice of using this spacing across the country regardless of the variety to be cultivated, the purpose of production (seed potato or ware potato), agro-ecology, etc. may lead to lower tuber yields. To elucidate this problem and the effect of plant spacing on the productivity of different potato varieties, field experiments were conducted in Hirna and Haramaya districts in the Hararghe Zones of Eastern Ethiopia. The treatments consisted of five plant spacing and four potato cultivars. The experiment at each location was laid out as a completely randomized block design in a factorial arrangement and replicated three times per treatment. Analysis of total, marketable and unmarketable tuber number per unit area obtained indicated that the effect of cultivar and spacing highly significantly $(p<0.01)$ influenced. The cultivar and plant spacing highly significant $(p<0.01)$ affect tubers size distribution. Total tuber yield responded highly significantly $(p<0.01)$ to the effects of cultivar and spacing. Results of the experiment revealed that keeping intra-row spacing of $25 \mathrm{~cm}$, the inter-row spacing of $50 \mathrm{~cm}$ and $60 \mathrm{~cm}$ produced total yield of potato tubers of 31.24 and 30.97 tone ha $^{-1}$ respectively, i.e. more than $41 \%$ the yield of commonly used spacing of $75 \mathrm{~cm} \times 30 \mathrm{~cm}$. The highest number of seed-sized tubers $(40-75 \mathrm{~g})$ was obtained at high planting density, i.e. $50 \mathrm{~cm} \times 25 \mathrm{~cm}$ and $60 \mathrm{~cm} \times 25 \mathrm{~cm}$. Since spacing $50 \mathrm{~cm}$ $x 25 \mathrm{~cm}$ requires more planting material and also makes inter-cultivation practices more difficult, the spacing of $60 \mathrm{~cm} \times 25 \mathrm{~cm}$ was recommended for maximizing production of both seed and ware potatoes.
\end{abstract} Article Information

Article History:

Received : 05-07-2015

Revised : 17-09-2015

Accepted : 21-09-2015

Keywords:

Potato

Tuber size

Intra-row

Inter-row

Spacing

*Corresponding Author:

Tesfa Binalfew

E-mail:

tesfa25@gmail.com

\section{INTRODUCTION}

Potato is one of the main tuber crops grown in Ethiopia. It is grown by approximately one million farmers (CSA, 2009). It is regarded as a high-potential food security crop because of its ability to provide a high yield of high-quality product per unit input with a shorter crop cycle (Adane et al., 2010).

Crop production could be increased either by improving the inherent genetic potential of the crop or through application of better agronomic management, such as use of optimum plant density. There are efforts to increase the productivity of the crop through developing improved cultivars. However, there are still many farmers who grow potato frequently giving less regard to optimal plant population density for production of ware and seed potatoes. Appropriate seed tuber size has very important implication on potato production in Ethiopia. Although all sizes of seed potatoes can grow into a crop, seed growers should only plant tubers range from $25-55 \mathrm{~mm}$ in diameter or 40-75 g in weight (Lung'aho et al., 2007).

One of the most important management practices for potato production is plant spacing. It depends on type of variety, fertility status of soil, plant architecture or growth habit etc. Potato varieties also differ on growth habit and other attributes. Therefore, using the same spacing for all varieties may not lead to optimum tuber yields.

The most common potato spacing in Ethiopia for ware potato production is $75 \mathrm{~cm}$ between rows and $30 \mathrm{~cm}$ between plants. However, farmers in eastern Ethiopia often use closer spacing for both ware and seed potatoes and claim that the narrower spacing increases tuber number without compromising tuber size for both seed and ware potato production.

Haramaya University has released several high yielding potato varieties. However, all the varieties are planted at the spacing of $75 \mathrm{~cm}$ between rows and $30 \mathrm{~cm}$ between plants. Thus, no efforts have been made to determine optimum spacing for the different varieties.

In general, there had been little research done to optimize plant spacing for maximum tuber yield for both ware and seed purposes. Hence, a curious investigation into cultivar differences in relation to plant population 
Tesfa Binalfew et al.,

densities was required for relevant recommendations to optimize seed and ware potato yields. Thus, the study was conducted with the objective of determining optimum plant spacing for maximum seed and ware tuber production of potato in Eastern Ethiopia.

\section{MATERIALS AND METHODS}

Experiment was carried out under rain-fed condition from July to Oct 2011 during the main cropping season at Haramaya and Hirna, Hararghe highlands of Eastern Ethiopia.

The Haramaya is located at an altitude of $1950 \mathrm{~m}$ above sea level at $9.0^{\circ}$ latitude and $42.0^{\circ}$ longitude. The mean annual rainfall and temperature of the study area was $790 \mathrm{~mm}$ and $16^{\circ} \mathrm{C}$, respectively. The site has a bimodal rainfall distribution and is representative of a subhumid mid-altitude agro-climatic zone. While the Hirna site is situated at $9^{\circ}$ latitude, $41^{\circ}$ longitude, and at an altitude of 1870 metres above sea level. The area receives mean annual rainfall $1000 \mathrm{~mm}$. The mean temperature of the area is $24{ }^{\circ} \mathrm{C}$.

The treatments consisted of four potato cultivars (Badhassa, Chala, Batte and Zemen) and five plant spacing between rows and plants, respectively: $(80 \mathrm{~cm} x$ $30 \mathrm{~cm}, 75 \mathrm{~cm} \times 30 \mathrm{~cm}, 60 \mathrm{~cm} \times 30 \mathrm{~cm}, 60 \mathrm{~cm} \times 25 \mathrm{~cm}$ and $50 \mathrm{~cm} \times 25 \mathrm{~cm}$ ). The experiments were laid out in $\mathrm{RCBD}$ in a factorial arrangement and replicated three times.

Significant tests were made by analysis of variance for Randomized Complete Block Design in factorial
Sci. Technol. Arts Res. J., July-Sep 2015, 4(3): 11-17

arrangement. The ANOVA was carried out using the General Linear Model of the SAS procedure of version 9.1. For factors showing significant effects, mean comparisons were made using the least significant difference (LSD) test at $5 \%$ level of significance.

\section{Data Collection and Measurements}

Days to $50 \%$ flowering, days to $50 \%$ maturity, plant height, leaf area index, stem number, average tuber number, average tuber weight, weight and number of marketable tubers and unmarketable tubers, total tuber number, total tuber yield, tuber size distribution, specific gravity, dry matter percentage and harvest index were taken.

\section{RESULTS AND DISCUSSION}

\section{Tuber Number}

The highest total tuber number per $\mathrm{m}^{2}$ was recorded at high planting density $(60 \mathrm{~cm} \times 25 \mathrm{~cm})$ and Badhasa cultivar treatment combination and the lowest number was observed at low planting density $(75 \mathrm{~cm} \times 30 \mathrm{~cm})$ with Chala cultivar. All cultivars produced their maximum tuber numbers at the narrow spacing than the wider one and there were gradual increments. Similarly, the interaction effect of plant spacing and cultivar on marketable tuber number was characterized with highly significant differences of high number of tuber for narrow spacing of $60 \mathrm{~cm} \times 25 \mathrm{~cm}$ and $50 \mathrm{~cm} \times 25 \mathrm{~cm}$ in combination with cultivar Bedhassa and Chala, and low number of tubers for wider spacing with combination of Chala and Batte cultivars at Hirna site (Table 1).

Table 1: The interaction effects of cultivar and plant spacing on potato tuber number per $\mathrm{m}^{2}$ at Hirna and Haramaya

\begin{tabular}{|c|c|c|c|c|c|}
\hline $\begin{array}{l}\text { Cultivar } \\
\text { (A) }\end{array}$ & $\begin{array}{l}\text { Spacing } \\
\text { (B) } \\
(\mathrm{cm} \times \mathrm{cm})\end{array}$ & $\begin{array}{c}\text { Total tuber } \\
\text { number } \\
\text { at Hirna }\end{array}$ & $\begin{array}{c}\text { Marketable } \\
\text { tuber number } \\
\text { at Hirna }\end{array}$ & $\begin{array}{c}\text { Unmarketable } \\
\text { tuber number } \\
\text { at Haramaya }\end{array}$ & $\begin{array}{c}\text { Very small } \\
\text { tuber at } \\
\text { Haramaya }(<25 \mathrm{~g})\end{array}$ \\
\hline \multirow{5}{*}{ Badhasa } & $80 \times 30$ & $61.80^{\mathrm{etg}}$ & $40.36^{\text {detg }}$ & $45.10^{\mathrm{DC}}$ & $44.30^{\circ \mathrm{C}}$ \\
\hline & $75 \times 30$ & $63.50^{\text {det }}$ & $45.03^{\mathrm{bcd}}$ & $31.00^{\text {detgh }}$ & $28.50^{\text {detgh }}$ \\
\hline & $60 \times 30$ & $75.20^{\text {cde }}$ & $46.58^{\text {bcd }}$ & $39.20^{\text {cdet }}$ & $36.70^{\text {cdet }}$ \\
\hline & $60 \times 25$ & $106.80^{a}$ & $65.39^{a}$ & $44.00^{\mathrm{bcd}}$ & $41.60^{\mathrm{bcd}}$ \\
\hline & $50 \times 25$ & $100.10^{\mathrm{ab}}$ & $62.94^{\mathrm{a}}$ & $54.50^{\mathrm{ab}}$ & $53.00^{\mathrm{ab}}$ \\
\hline \multirow{5}{*}{ Chala } & $80 \times 30$ & $41.30^{g h}$ & $25.67^{\text {gh }}$ & $22.40^{\text {ghiJ }}$ & $17.60^{\text {hIJk }}$ \\
\hline & $75 \times 30$ & $38.80^{\mathrm{h}}$ & $23.90^{n}$ & $17.60^{\mathrm{hIJ}}$ & $13.80^{\mathrm{k}}$ \\
\hline & $60 \times 30$ & $45.30^{\operatorname{tgn}}$ & $28.11^{\text {gn }}$ & $25.30^{\operatorname{tgh} ı}$ & $18.90^{\text {hıjk }}$ \\
\hline & $60 \times 25$ & $70.60^{\text {cde }}$ & $43.98^{\mathrm{bcd}}$ & $27.70^{\text {tghı }}$ & $22.00^{\text {ghi }}$ \\
\hline & $50 \times 25$ & $102.00^{\mathrm{ab}}$ & $63.66^{a}$ & $34.40^{\text {cdefg }}$ & $29.90^{\text {defgh }}$ \\
\hline \multirow{5}{*}{ Batte } & $80 \times 30$ & $39.50^{h}$ & $25.57^{g h}$ & $9.10^{\prime}$ & $8.00^{\mathrm{K}}$ \\
\hline & $75 \times 30$ & $58.20^{\text {etg }}$ & $33.20^{\text {fghij }}$ & $16.70^{\mathrm{ij}}$ & $15.20^{\mathrm{ijk}}$ \\
\hline & $60 \times 30$ & $44.60^{\operatorname{tgn}}$ & $28.74^{\operatorname{tgn}}$ & $24.50^{g h ı}$ & $23.30^{\text {tghi }}$ \\
\hline & $60 \times 25$ & $88.10^{\mathrm{bc}}$ & $52.19^{b c}$ & $26.70^{\operatorname{tgn} 1}$ & $25.10^{\text {tghi }}$ \\
\hline & $50 \times 25$ & $80.00^{\mathrm{cd}}$ & $48.35^{\mathrm{cd}}$ & $26.80^{\operatorname{tgh} ı}$ & $24.40^{\text {tghij }}$ \\
\hline \multirow{5}{*}{ Zemen } & $80 \times 30$ & $64.70^{\text {det }}$ & $26.42^{\text {gh }}$ & $28.90^{\text {etghı }}$ & $27.20^{\text {efghiJ }}$ \\
\hline & $75 \times 30$ & $69.30^{\mathrm{de}}$ & $32.11^{\mathrm{ghl}}$ & $22.40^{\text {ghl }}$ & $20.30^{\text {hIJk }}$ \\
\hline & $60 \times 30$ & $68.50^{\text {de }}$ & $34.03^{\text {etghı }}$ & $35.70^{\text {cdetg }}$ & $34.60^{\text {cdetg }}$ \\
\hline & $60 \times 25$ & $79.70^{\mathrm{cd}}$ & $44.39^{\mathrm{bcd}}$ & $61.70^{\mathrm{a}}$ & $59.30^{\mathrm{a}}$ \\
\hline & $50 \times 25$ & $87.60^{\mathrm{bc}}$ & $38.06^{\operatorname{detgn}}$ & $42.70^{\text {bcde }}$ & $40.20^{\text {bcde }}$ \\
\hline \multirow{2}{*}{\multicolumn{2}{|c|}{$\begin{array}{r}\operatorname{LSD}(\mathrm{AxB})_{(0.05)} \\
\mathrm{CV} \%\end{array}$}} & 17.70 & 10.93 & 9.58 & 13.46 \\
\hline & & 15.50 & 16.20 & 14.30 & 27.90 \\
\hline
\end{tabular}

Means followed by the same letter within a column are not significantly different at $5 \%$ level of significance

At Haramaya, cultivar Badhasa produced significantly higher number of total and marketable tubers over the other cultivars while the lowest number was observed for Chala. The cultivars also had high and low tuber numbers in the respective tuber size categories. Badhasa exceeded Chala, Batte and Zemen by 87,86 and $30 \%$ in total tuber numbers, respectively. Similarly, Chala attained only $45 \%$ of marketable tuber numbers that Badhasa attained. The main effect of spacing influenced the total and marketable tuber numbers including tuber size 
Tesfa Binalfew et alo,

categories at Haramaya. Generally, as plant spacing reduced, there was a trend increasing tuber number. Medium-sized (40-75 g) seed tubers increased as spacing reduced, wider plant spacings of $80 \mathrm{~cm} \times 30 \mathrm{~cm}$ and 75 $\mathrm{cm} \times 30 \mathrm{~cm}$ producing lower number of tubers while closer spacing of $50 \mathrm{~cm} \times 25 \mathrm{~cm}$ and $60 \mathrm{~cm} \times 25 \mathrm{~cm}$ producing higher tuber number per $\mathrm{m}^{2}$ (Table 1)

Analysis of the pooled mean of total, marketable and unmarketable tuber numbers as well as very small, small, medium and large tuber numbers categories at the two locations indicated that the cultivars and spacing treatments did not affect these parameters. Badhasa attained the highest total, marketable and unmarketable tuber numbers. Similarly, when this record cascaded into size categories, high numbers of very small, small, medium and large tubers were observed for this cultivar than others. Badhasa exceeded Chala, Batte, and Zemen within total tuber numbers by 53,55 and $20 \%$ in marketable tuber number by 100,52 and $51 \%$ and in medium-sized potato tuber numbers by 77,64 and $61 \%$, respectively. Regarding spacing used, narrow spacing of $50 \mathrm{~cm} \times 25 \mathrm{~cm}$ and $60 \mathrm{~cm} \times 25 \mathrm{~cm}$ resulted in the higher numbers of total, marketable and unmarketable tubers than wider spacing of $80 \mathrm{~cm} \times 30 \mathrm{~cm}$ and $75 \mathrm{~cm} \times 30 \mathrm{~cm}$. All four tubers size categories behaved in a similar way that as spacing became narrower the number of respective tuber categories increased. Narrow spacing of $50 \mathrm{~cm} \times 25 \mathrm{~cm}$ resulted in 58,62, 42 and $6 \%$ more total tuber numbers over spacing of $80 \mathrm{~cm} \times 30 \mathrm{~cm}, 75 \mathrm{~cm} \times 30$ $\mathrm{cm}, 60 \mathrm{~cm} \times 30 \mathrm{~cm}$ and $60 \mathrm{~cm} \times 25 \mathrm{~cm}$, respectively (Table 2). Generally, narrow spacing $50 \mathrm{~cm} \times 25 \mathrm{~cm}$ and $60 \mathrm{~cm} \times 25 \mathrm{~cm}$ were characterized with high number of tubers while wider spacings were observed with low numbers of tubers. The current study is in agreement with the results of different authors; high plant densities should be used to produce relatively large number of seed size tubers (Beukema and Van der Zaag, 1990).

The total number of tubers per unit area increased linearly with increasing density. Allen and Wurr (1992) also found that the total number of tubers increased with seed size and reduction of spacing. However, the total number of tubers per stem decreased with increasing seed size and reduced spacing.

\section{Tuber Yield}

At Haramaya, cultivar Badhasa had most significantly highest total tuber yield while Chala, Batte and Zemen had lower total tuber yields, which were in statistical parity with each other. Hence, the total tuber yield of Badhasa exceeded those of Batte, Chala and Zemen by 54, 46 and $38 \%$, respectively. On the other hand, as plant spacing reduced, there was an increasing trend in total tuber yield. In this regard, decreasing spacing of $75 \mathrm{~cm} \times 30 \mathrm{~cm}$ to 60 $\mathrm{cm} \times 25 \mathrm{~cm}$ resulted in total tuber yield increment by $41.9 \%$ (Table 3 ).

Similarly, at Hirna cultivar Badhasa had the highest total tuber yield (36.25 ton ha ${ }^{-1}$ ), which was $44.25,27.37$ and $40.78 \%$ more over Chala, Batte and Zemen, respectively. Significant effects were observed among plant spacings in such a way that closer spacing of $50 \mathrm{~cm}$ $\times 25 \mathrm{~cm}$ and $60 \mathrm{~cm} \times 25 \mathrm{~cm}$ resulted in the higher total tuber yields. But, wider spacing of $80 \mathrm{~cm} \times 30 \mathrm{~cm}$ and 75 $\mathrm{cm} \times 30 \mathrm{~cm}$ resulted in lower total tuber yields. Generally, there was a consistent increment in total tuber yields as plant spacing increased from $50 \mathrm{~cm} \times 25 \mathrm{~cm}$ to wider
Sci. Technol. Arts Res. J., July-Sep 2015, 4(3): 11-17

spacing $80 \mathrm{~cm} \times 30 \mathrm{~cm}$ in such a way that yield at spacing of $50 \mathrm{~cm} \times 25 \mathrm{~cm}>60 \mathrm{~cm} \times 25 \mathrm{~cm}>60 \mathrm{~cm} \times 30 \mathrm{~cm}>75$ $\mathrm{cm} \times 30 \mathrm{~cm}>80 \mathrm{~cm} \times 30 \mathrm{~cm}$. Hirna growing environment resulted in higher total tuber yields of all cultivars than Haramaya at all spacings used. At Hirna, cultivars Badhasa, Chala, Batte and Zemen gave total tuber yields with additional increments of 22, 24, 48 and $19 \%$, respectively, when compared to the yields obtained at Haramaya (Table 3). This might be due to suitable environmental conditions for potato production at Hirna.

Considering the overall mean of total tuber yield of the two locations, cultivar Badhasa produced significantly higher total tuber yields than the other cultivars. On the other hand, the cultivars Chala, Batte and Zemen produced the lower total tuber yields, which were in statistical parity. Thus, Badhasa exceeded Chala, Batte and Zemen by 45,38 and $39 \%$ in total tuber yields, respectively.

On the other hand, the closer planting spacings of 50 $\mathrm{cm} \times 25 \mathrm{~cm}$ and $60 \mathrm{~cm} \times 25 \mathrm{~cm}$ led to similar higher total tuber yields than the wider spacing of $80 \mathrm{~cm} \times 30 \mathrm{~cm}$ and $75 \mathrm{~cm} \times 30 \mathrm{~cm}$. Generally, as plant spacing reduced, there was an increasing trend in total tuber yields of the plants. From this study, it has been observed that keeping the intra-plant spacing $25 \mathrm{~cm}$ and inter-row spacing of 50 and $60 \mathrm{~cm}$ resulted in increased total tuber yields compared to the commonly used spacing of $75 \mathrm{~cm} \times 30$ cm by 43 and $42 \%$, respectively (Table 3 ).

The increased yield at higher densities may be attributed to the higher ground covered with green leaves earlier (earlier in the season, light is intercepted and used for assimilation), fewer lateral branches being formed and tuber growth starting earlier. To produce smaller tubers, higher plant densities are needed than for the production of big tubers. Consistent with this suggestion, increased plant population density increased yield due to more tubers being harvested per unit area of land (Beukema and Van der Zaag, 1990). However, decreases in total yields as a result of wider spacing were compensated for in part by increased production of large-sized tubers and decreased production of small-sized tuber. This is apparently a result of reduced interplant competition, which leads to increased production of total tuber numbers per plant and increased average tuber size with wider seed piece spacing (Rex et al, 1987).

The results of the current investigation also support the findings of various authors. Entz and Entz and LaCroix, (1984) found reduction in the production of total yield in response to increased intra-row spacing. Similarly, Nelson (1967) found that higher population density resulted in slightly higher total yields and a greater number of small tubers.

\section{Marketable Tuber Yield}

At Hirna, the observed treatment means of the main effect of cultivar affected marketable tuber yield. Cultivar Badhasa produced the highest marketable tuber yield than others, exceeding the marketable tuber yield of Chala, Batte and Zemen by 59, 29 and 59\% of, respectively. Similarly, the main effect of plant spacing highly influenced the yield of marketable tubers; as plant spacing reduced, the yield of marketable tuber increased consistently. Closer spacing of $50 \mathrm{~cm} \times 25 \mathrm{~cm}$ and $60 \mathrm{~cm}$ $\times 25 \mathrm{~cm}$ produced higher marketable tuber yield whereas 

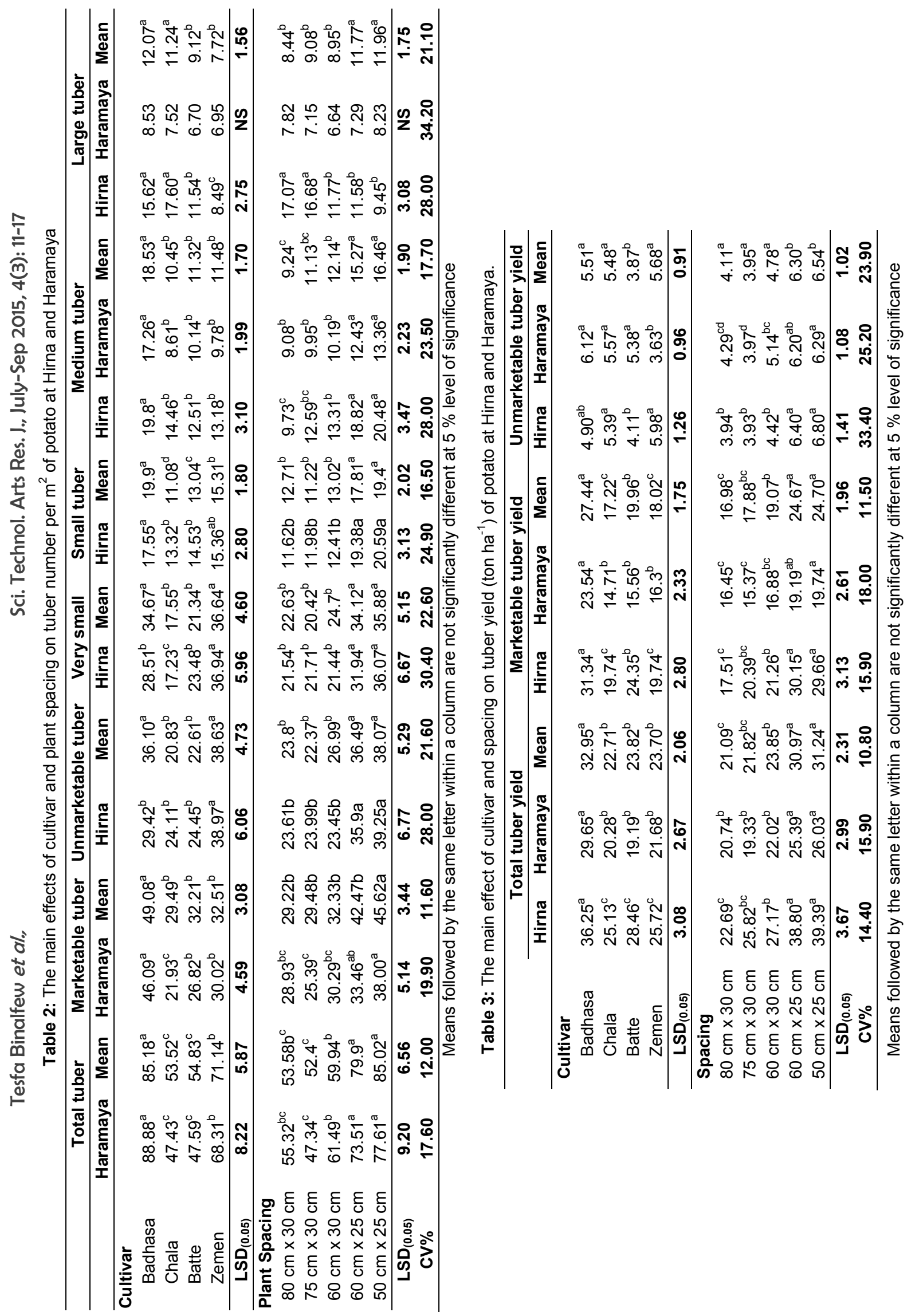
Tesfa Binalfew et alo,

wider spacing of $80 \mathrm{~cm} \times 30 \mathrm{~cm}$ and $75 \mathrm{~cm} \times 30 \mathrm{~cm}$ led to the production of lower marketable tuber yields. For example, the marketable tuber yields obtained in response to planting the potato crop at the narrower spacing of $60 \mathrm{~cm} \times 25 \mathrm{~cm}$ exceeded the marketable tuber yield obtained in response to the spacing of $80 \mathrm{~cm} \times 30$ $\mathrm{cm}$ and $75 \mathrm{~cm} \times 30$ by 72 and $48 \%$, respectively.

Under Haramaya condition, cultivar Badhasa produced higher marketable tuber yield whereas cultivar Chala, Batte and Zemen produced significantly lower marketable yields than Badhasa, which were in a statistical parity. In response to reducing plant spacing, marketable tuber yield increased too. Closer spacing of $50 \mathrm{~cm} \times 25 \mathrm{~cm}$ yielded $\left(19.74\right.$ tonnes $\left.\mathrm{ha}^{-1}\right)$, leading to the production of $20,28.6,16.94$ and $2.87 \%$ higher amounts of marketable tuber yields than the marketable tuber yields attained at the spacings of $80 \mathrm{~cm} \times 30 \mathrm{~cm}, 75 \mathrm{~cm} \times 30 \mathrm{~cm}, 60 \mathrm{~cm} \times$ $30 \mathrm{~cm}$ and $60 \mathrm{~cm} \times 25 \mathrm{~cm}$, respectively (Table 3). The higher marketable tuber yield at higher planting density may be attributed to the effect of efficient use and less competition between plants for available soil nutrients.

Similarly, the highest mean marketable tuber yield of the two locations was obtained from Badhasa cultivar. Chala and Zemen had the lowest and statistically similar marketable tuber yields. Similar to the yields obtained at two locations, the mean value of marketable tuber yields consistently increased in response to reduction in plant spacing. The narrowest spacing of $50 \mathrm{~cm} \times 25 \mathrm{~cm}$ exceeded in marketable yield the spacing of $60 \mathrm{~cm} \times 25$ $\mathrm{cm}, 60 \mathrm{~cm} \times 30 \mathrm{~cm}, 75 \mathrm{~cm} \times 30$ and $80 \mathrm{~cm} \times 30 \mathrm{~cm}$ by about $0.12,29.5,38.14$ and $45.46 \%$, respectively (Table $3)$. The higher marketable tuber yield at high planting density might be attributed to the effect of producing higher number of tubers due to the efficient and competitive utilization nutrients. This result is supported by the results of experiments done in Sudan, which revealed that marketable tuber yield of close in-row spacing of $15 \mathrm{~cm}$ and $25 \mathrm{~cm}$ increased and out-yielded wider $(35 \mathrm{~cm})$ spacing by $26 \%$ (Khalafalla, 2001).
Sci. Technol. Arts Res. J., July-Sep 2015, 4(3): 11-17

\section{Unmarketable Tuber Yield}

Cultivar Batte had significantly lower unmarketable tuber yield while Zemen and Chala had significantly higher unmarketable yield. But at Haramaya, cultivar Zemen had significantly the lowest unmarketable tuber yield while Badhasa and Batte had high amounts of unmarketable tuber yield. Generally, from the mean result of the two locations, Cultivar Batte had 29.4, 29.8 and $31.9 \%$ less unmarketable tuber yield compared to Chala, Badhasa and Zemen cultivars, respectively (Table 3). Unmarketable tuber yield of potato was influenced by plant spacing. High unmarketable tuber yields were obtained in response to high planting density while wider spacing of $80 \mathrm{~cm} \times 30 \mathrm{~cm}$ and $75 \mathrm{~cm} \times 30 \mathrm{~cm}$ resulted in lower unmarketable tuber yields. As spacing increased from $50 \mathrm{~cm} \times 25 \mathrm{~cm}$ to $80 \mathrm{~cm} \times 30 \mathrm{~cm}$, the unmarketable tuber yield reduced by $72.22 \%$ at Hirna. This could be attributed to the facts that, under narrower spacing, a higher proportion of undersized tubers are produced, which are unmarketable. Frezgi Asgedom (2007) also reported that closest spacing resulted in significantly higher yield of small-sized tubers as the consequence of stiffer competitions between plants for resources such as moisture, nutrients, and light.

\section{Effect of Plant Spacing and Cultivar on Tuber Size Distribution}

Very Small Tuber Size $(<25 \mathrm{~g})$ : In terms of the yield of very small tuber size potatoes, cultivars responded differently to the spacing treatment at Haramaya. The highest yield of very small tuber size potato was observed with treatment combination of Zemen cultivar at the spacing of $60 \mathrm{~cm} \times 25 \mathrm{~cm}$, which is more than $500 \%$ of the lowest yield with treatment combination of Batte cultivar at spacing of $80 \mathrm{~cm} \times 30 \mathrm{~cm}$. All cultivars had higher yields of small-sized tubers when they were combined with lower plant spacing; however the yield reduced as spacing was widened. For example, Batte gave 174 and $38 \%$ more yield of very small-sized tubers at the spacing of $60 \mathrm{~cm} \times 25 \mathrm{~cm}$ than at spacing of $80 \mathrm{~cm}$ x $30 \mathrm{~cm}, 75 \mathrm{~cm} \times 30 \mathrm{~cm}$, respectively (Table 4).

Table 4: The interaction effects of cultivar and spacing on yield (ton $\mathrm{ha}^{-1}$ ) of very small tuber size potato (tubers less than $25 \mathrm{~g}$ ) at Haramaya

\begin{tabular}{|c|c|c|c|c|c|}
\hline \multirow[b]{2}{*}{ Cultivar } & \multicolumn{5}{|c|}{ Spacing } \\
\hline & $80 \mathrm{~cm} \times 30 \mathrm{~cm}$ & $75 \mathrm{~cm} \times 30 \mathrm{~cm}$ & $60 \mathrm{~cm} \times 30 \mathrm{~cm}$ & $60 \mathrm{~cm} \times 25 \mathrm{~cm}$ & $50 \mathrm{~cm} \times 25 \mathrm{~cm}$ \\
\hline Badhasa & $5.68^{\mathrm{abc}}$ & $3.61^{\text {def }}$ & $4.48^{\mathrm{cd}}$ & $5.67^{\mathrm{abc}}$ & $6.61^{\mathrm{ab}}$ \\
\hline Chala & $2.28^{\mathrm{efg}}$ & $1.97^{\mathrm{fg}}$ & $2.53^{\text {efg }}$ & $2.44^{\mathrm{efg}}$ & $4.62^{\mathrm{cd}}$ \\
\hline Batte & $1.22^{\mathrm{g}}$ & $2.43^{\text {efg }}$ & $3.36^{\text {def }}$ & $3.35^{\mathrm{def}}$ & $3.32^{\mathrm{def}}$ \\
\hline Zemen & $3.28^{\text {def }}$ & $2.66^{\mathrm{efg}}$ & $4.03^{\mathrm{cde}}$ & $7.37^{\mathrm{a}}$ & $5.00^{\mathrm{bcd}}$ \\
\hline \multicolumn{6}{|c|}{$\operatorname{LSD}(A x B)_{(0.5)}=1.76$} \\
\hline & $C V \%=28.00$ & & & & \\
\hline
\end{tabular}

At Hirna, Cultivar Zemen and Badhasa had significantly higher yields of very small-sized tubers than others such as Chala and Batte which produced lower yields of very small-sized tubers. On other hand, yield of very small-sized tubers increased at higher planting density. Thus, the maximum yield of very small-sized tubers was recorded for high planting density, i.e. $50 \mathrm{~cm} \mathrm{x}$ $25 \mathrm{~cm}$ and low yield was recorded for low planting density i.e. $75 \mathrm{~cm}$ inter row spacing and $30 \mathrm{~cm}$ intra row spacing. On the other hand, Badhasa and Zemen cultivars had higher yields of very small-sized tubers while Chala had the smallest yield of very small-sized tubers (Table 5). This might be the inherent characteristics of the cultivars used.

The analysis of the overall mean of the yields of very small-sized tubers at the two locations indicated that among cultivars Badhasa and Zemen had the highest while Chala and Batte produced the lowest yield of very small-sized tubers. Close spacing of $50 \mathrm{~cm} \times 25 \mathrm{~cm}$ resulted in the highest and gradually decreasing yields of very small-sized tubers as the spacing was increased. 
Tesfa Binalfew et alo,

The yield of very small-sized tubers at the spacing of 50 $\mathrm{cm} \times 25 \mathrm{~cm}$ exceeded that produced at spacing of $80 \mathrm{~cm}$ x $30 \mathrm{~cm}$ and $75 \mathrm{~cm} \times 30 \mathrm{~cm}$ by 91 and $69 \%$, respectively (Table 5). The reason for this might be that close planting restricted tuber sizing and resulted in an excessive proportion of very small tubers which is attributed to increased competition between plants (Mass, 1963). Generally, with increasing plant density, the number of tubers produced was increased. Thus, it could be argued that increase in the number of tubers may result in increasing in tuber weight per unit area. However, increase in density may increase the competition between and within the plants and hence, lead to decrease in availability of nutrients for each plant. As a result, there would be a decline in mean tuber weight (Karafyllidis et al., 1997).

Very small tuber size potatoes are undersized and are not marketable; therefore, positively and highly significant correlation is found with unmarketable tuber yield $\left(r=0.68^{\star *}\right)$ and number.

Small Tuber Size (25-39 g): The cultivar Badhasa had significantly higher small tuber yield at both Hirna and Haramaya. However, cultivar Chala produced the lowest small tuber yield at Hirna and Haramaya. Cultivar Batte also produced lower small-sized tubers at Haramaya. The lowest percent of small tuber yield was observed with cultivar Chala while all the rest were hight and were in statistically uniform. Similarly, small tuber yield increment was observed at higher planting density than at lower planting density at both Hirna and Haramaya (Table 5).

In general, as indicated by the mean of the two locations, the highest yield of small-sized tubers was observed for Badhasa cultivar whereas Chala had the lowest yield of small-sized tubers. This difference might be due to the genetic potential of the potato cultivars for yield. Concerning the influence of spacing on yield of
Sci. Technol. Arts Res. J., July-Sep 2015, 4(3): 11-17

small-sized tubers, as plant spacing decreased from 80 $\mathrm{cm} \times 30 \mathrm{~cm}$ to $50 \mathrm{~cm} \times 25 \mathrm{~cm}$, the yield of small-sized tubers increased by $55.64 \%$ (Table 5 ). The highest yield of small-sized tubers at higher planting density might be due to the fact that higher seed- piece spacing exerted a measurable effect on the yield of small potatoes. Corroborating the results of this study, Ounsworth (1963) found seed piece spacing exerted a measurable effect on the yield of small tubers in which the closer spacing resulted in significantly greater yields of small potatoes than the wider spacing. Similarly, Nelson (1967) also noted that higher population density resulted in slightly higher total yields and a greater number of small tubers.

Medium Tuber Size (40-75 g): Cultivar Badhasa produced significantly the highest yield of medium-sized tubers at Hirna as well as at Haramaya. The other cultivars Chala, Batte and Zemen produced lower yields of medium-sized tubers. Mean value of the yield of medium-sized tubers at the two locations was such that Badhasa produced significantly higher yield than the other cultivars whereas Chala produced the lowest yield of medium-sized tubers (Table 5).

Concerning plant spacing, higher yields of mediumsized tubers were obtained as spacing was reduced. The lowest share of medium size tuber yield was obtained from spacing of $80 \mathrm{~cm} \times 30 \mathrm{~cm}$ and $75 \mathrm{~cm} \times 30 \mathrm{~cm}$ while shares were observed on the rest and they are statistically the same. Generally, maximum yields of medium-sized tubers were recorded for closer inter-row spacing $(50 \mathrm{~cm}$ and $60 \mathrm{~cm}$ ) and intra row spacing $(25 \mathrm{~cm})$, and as spacing used was increased. For example, as indicated by the mean yield of the medium-sized tubers of the two locations spacing of $50 \mathrm{~cm} \times 25 \mathrm{~cm}$ out-yielded the spacing of $80 \mathrm{~cm} \times 30 \mathrm{~cm}, 75 \mathrm{~cm} \times 30 \mathrm{~cm}, 60 \mathrm{~cm} \times 30 \mathrm{~cm}$ and $50 \mathrm{~cm} \times 25 \mathrm{~cm}$, by $72,44,23$, and $6 \%$, respectively (Table 5).

Table 5: The main effect of cultivar and spacing on tuber size distribution yield (ton ha ${ }^{-1}$ ) of potato at Hirna and Haramaya

\begin{tabular}{|c|c|c|c|c|c|c|c|c|c|c|c|}
\hline & \multicolumn{2}{|c|}{$\begin{array}{l}\text { Very small } \\
\text { tuber yield }\end{array}$} & \multicolumn{3}{|c|}{ Small tuber yield } & \multicolumn{3}{|c|}{ Medium tuber yield } & \multicolumn{3}{|c|}{ Large tuber yield } \\
\hline & Hirna & Mean & Hirna & Haramaya & Mean & Hirna & Haramaya & Mean & Hirna & Haramaya & Mean \\
\hline \multicolumn{12}{|l|}{ Cultivar } \\
\hline Badhasa & $4.43^{a}$ & $4.82^{\mathrm{a}}$ & $6.4^{\mathrm{a}}$ & $7.17^{\mathrm{a}}$ & $6.78^{\mathrm{a}}$ & $10.62^{a}$ & $9.01^{a}$ & $9.82^{\mathrm{a}}$ & $14.8^{\mathrm{a}}$ & 8.27 & $11.53^{\mathrm{a}}$ \\
\hline Chala & $1.64^{c}$ & $2.2^{\mathrm{a}}$ & $2.89^{c}$ & $3.87^{\mathrm{c}}$ & $3.37^{\mathrm{C}}$ & $5.8^{\mathrm{C}}$ & $5.30^{b}$ & $5.55^{c}$ & $14.8^{\mathrm{a}}$ & 8.35 & $11.58^{\circ}$ \\
\hline Batte & $3.41^{\mathrm{b}}$ & $3.07^{\mathrm{b}}$ & $5.06^{b}$ & $3.81^{c}$ & $4.44^{\mathrm{b}}$ & $7.36^{\mathrm{b}}$ & $5.62^{b}$ & $6.49^{b}$ & $12.63^{\mathrm{a}}$ & 7.02 & $9.83^{b}$ \\
\hline Zemen & $4.94^{\mathrm{a}}$ & $4.7^{\mathrm{c}}$ & $4.92^{\mathrm{b}}$ & $4.91^{\mathrm{b}}$ & $4.91^{b}$ & $6.76^{\mathrm{bc}}$ & $5.28^{\mathrm{b}}$ & $6.02^{\mathrm{bc}}$ & $9.1^{\mathrm{b}}$ & 7.03 & $8.06^{\mathrm{c}}$ \\
\hline $\operatorname{LSD}_{(0.05)}$ & 0.92 & 0.67 & 1.15 & 0.97 & 0.79 & 1.52 & 1.12 & 0.86 & 2.41 & NS & 1.65 \\
\hline \multicolumn{12}{|l|}{ Spacing } \\
\hline $80 \mathrm{~cm} \times 30 \mathrm{~cm}$ & $2.78^{\mathrm{b}}$ & $2.95^{b c}$ & $3.93^{b}$ & $4.05^{b}$ & $3.99^{b}$ & $5.11^{c}$ & $4.929^{b}$ & $5.02^{d}$ & $9.63^{b}$ & 8.65 & $9.14^{b}$ \\
\hline $75 \mathrm{~cm} \times 30 \mathrm{~cm}$ & $2.56^{b}$ & $2.61^{c}$ & $4.15^{b}$ & $3.73^{b}$ & $3.94^{b}$ & $6.45^{b c}$ & $5.524^{b}$ & $5.99^{c}$ & $11.16^{b}$ & 7.41 & $9.28^{b}$ \\
\hline $60 \mathrm{~cm} \times 30 \mathrm{~cm}$ & $3.26^{b}$ & $3.43^{b}$ & $4.07^{b}$ & $4.72^{b}$ & $4.39^{b}$ & $7.09^{b}$ & $6.97^{a}$ & $7.03^{b}$ & $11.27^{b}$ & 6.73 & $9^{b}$ \\
\hline $60 \mathrm{~cm} \times 25 \mathrm{~cm}$ & $4.35^{\mathrm{a}}$ & $4.53^{a}$ & $5.82^{a}$ & $5.89^{a}$ & $5.85^{\mathrm{a}}$ & $9.43^{\mathrm{a}}$ & $6.925^{\mathrm{a}}$ & $8.18^{a}$ & $16.95^{\mathrm{a}}$ & 7.88 & $12.41^{\circ}$ \\
\hline $50 \mathrm{~cm} \times 25 \mathrm{~cm}$ & $5.08^{\mathrm{a}}$ & $4.98^{\mathrm{a}}$ & $6.13^{\mathrm{a}}$ & $6.30^{\mathrm{a}}$ & $6.21^{\mathrm{a}}$ & $10.09^{a}$ & $7.156^{\mathrm{a}}$ & $8.63^{a}$ & $15.16^{a}$ & 7.68 & $11.42^{\circ}$ \\
\hline $\operatorname{LSD}_{(0.05)}$ & 1.03 & 0.75 & 1.28 & 1.08 & 0.88 & 1.70 & 1.25 & 0.96 & 2.69 & NS & 1.84 \\
\hline CV\% & 34.40 & 24.50 & 32.20 & 26.60 & 21.90 & 27.00 & 24.10 & 16.60 & 25.40 & 37.00 & 21.70 \\
\hline
\end{tabular}

Large Tuber Size (>75 g): At Hirna, cultivars Zemen had significantly lower yield of large-sized tubers than Badhasa, Batte and Challa. The rest three cultivars were high in yield large-sized tubers, which were in a statistical parity. Hence, yield of large-sized tubers of Zemen was exceeded by 38,38 and $28 \%$ by the yields of large-sized 
tubers of Badhasa, Chala and Batte cultivars, respectively. Significantly higher yield of large-sized tubers was recorded at narrower spacing of $60 \mathrm{~cm} \times 25$ and $50 \mathrm{~cm} \times 25 \mathrm{~cm}$ while spacing of $80 \mathrm{~cm} \times 30 \mathrm{~cm}, 75$ $\mathrm{cm} \times 30 \mathrm{~cm}$ and $60 \mathrm{~cm} \times 30 \mathrm{~cm}$ observed with lower yield of large-sized tubers. Therefore, spacing of $60 \mathrm{~cm} \times 25$ $\mathrm{cm}$ produced 76,51 and $50 \%$ more yield of large-sized tubers over spacing of $80 \mathrm{~cm} \times 30 \mathrm{~cm}, 75 \mathrm{~cm} \times 30 \mathrm{~cm}$ and $60 \mathrm{~cm} \times 30 \mathrm{~cm}$, respectively. The highest share of large sized tuber yield obtained with wide spacing of $80 \mathrm{~cm} \times 30$ $\mathrm{cm}$ and $75 \mathrm{~cm} \times 30 \mathrm{~cm}, 44.7$ and $43.26 \%$ respectively (Table 5).

Considering the mean yield of large-sized tubers at the two locations, close spacing of $60 \mathrm{~cm} \times 25 \mathrm{~cm}$ and $50 \mathrm{~cm}$ $x 25$ resulted in higher yields of large-sized tubers where wider spacing at $80 \mathrm{~cm} \times 30 \mathrm{~cm}$ and $75 \mathrm{~cm} \times 30 \mathrm{~cm}$ resulted in reduced yields of large-sized tubers. Thus, the highest large-sized tuber yield was recorded at $60 \mathrm{~cm}$ inter row spacing and $25 \mathrm{~cm}$ intra row spacing, which was $33.7 \%$ higher than the yield of large-sized tubers recorded at $75 \mathrm{~cm} \times 30 \mathrm{~cm}$ planting spacing. This might be because low density planting leaves spaces, which is not economical with respect to efficient use of land and nutrients. This means that, narrower spacing that is often used by the research system in Ethiopia is still too wide for most of our potato varieties as they have narrower canopy and would be wasting light and soil nutrients as resource for growth, development, and production of carbohydrate and yield, when they are planted at wider spacing (Table 5).

\section{CONCLUSION}

In conclusion, cultivar Badhasa was the highest yielding variety compared to the other three varieties, which produced lower yields with statistical parity. The spacing of $50 \mathrm{~cm} \times 25 \mathrm{~cm}$ and $60 \mathrm{~cm} \times 25 \mathrm{~cm}$ led to the production of maximum seed as well as ware (marketable) tuber yields and numbers. However, when the high seed tuber requirements for the spacing of $50 \mathrm{~cm}$ $x 25 \mathrm{~cm}$ as well as the relatively more difficulty it poses to inter-cultivation are considered, the spacing of $60 \mathrm{~cm} \times 25$ $\mathrm{cm}$ is optimal for high productivity of ware as well as seed potatoes in the region. Therefore, the current recommendation of using the spacing of $75 \mathrm{~cm}$ between rows and $30 \mathrm{~cm}$ between plants for all areas in the country should be revised and optimum spacing determined for specific regions.

\section{Conflict of Interest}

None declared.

\section{Acknowledgements}

The authors would like to thank Wagenigen University International, Centre for Innovation and Development, as well as Haramaya University (HU) for financing the MSc research through the Local Seed Business (LSB) project.

\section{REFERENCES}

Adane, H., Meuwissen, M.P.M., Agajie, T., Lommen, W.J.M., Lansink, A.O., Admasu, T., Struik, P.C. (2010). Analysis of Seed Potato Systems in Ethiopia. American Journal of Potato Research 87(6): 537-552.

Allen, E.J., Wurr, D.C.E. (1992). Plant density. In Harris: The Potato Crop: The Scientific Basis for Improvement. pp. 292-330. $2^{\text {nd }}$ Edition. Chapman and Hall, London.

Beukema, H.P., Van der Zaag, D.E. (1990). Introduction to Potato Production. Pudoc Wageningen, The Netherlands.

CSA (Central Statistical Agency) (2009). Agricultural sample survey: Report on area and production of crops, Addis Abeba, Ethiopia.

Entz, M.H., LaCroix, L.J. (1984). The effect of in-row spacing and seed type on the yield and quality of a potato cultivar American Potato Journal 61: 93-104.

Frezgi, A. (2007). Effect of Planting Density and Nitrogen Application on Yield and Yield Components of Potato (Solanum tuberosum L.) at Enderta, Southern Tigray, Ethiopia. MSc. Thesis submitted to school of plant sciences, Haramaya University, Ethiopia.

Karafyllidis, D.I., Georgakis, D.N., Stavropoulos, N.I. Nianiou, E.X., Vezyroglou, I.A. (1997). Effect of planting density and size of potato seed-minitubers on their yielding capacity. Acta Horticulturae 462: 943-950.

Khalafalla, A.M. (2001). Effect of Plant Density and Seed Size on Growth and Yield of Solanum Potato in Khartoum State, Sudan. African Crop Science Journal 9(1): 77-82.

Lung'aho, C., Lemaga, B., Nyongesa, M., Gildemacher, P. Kinyae, P., Demo, P., Kabira, J. (2007). Commercial seed potato Production in eastern and central Africa. Kenya Agricultural Research Institute.

Mass, E.F. (1963). The effect of seed spacing and nitrogen levels on the size of Netted Gem potatoes. American Potato Journal 40:133-139.

Nelson, D.C. (1967). Effect of row spacing and plant populations on yields and tuber-size of potatoes. American Potato Journal 44: 17-13.

Ounsworth, L.F. (1963). Production of small protatoes for whole pack canning. American Potato Journal 40: 430434

Rex, B.L., Russell, W.A. (1987). The effect of spacing of seed species on yields quality and economic value for processing of Shepody potato in Manitoba. American Potato Journal 64(4): 177-189. 